\title{
Congenital Jejunal Stenosis
}

National Cancer Institute

\section{Source}

National Cancer Institute. Congenital Jejunal Stenosis. NCI Thesaurus. Code C102985.

Narrowing of the lumen of the jejunum that is present at birth. 